\title{
POSSIBILITIES OF PLANAR CAPACITIVE RAIN SENSOR MANUFACTURING BY THICK FILM TECHNOLOGY
}

\author{
Samuel ŽUK, Alena PIETRIKOVÁ, Igor VEHEC \\ Department of Technologies in Electronics, Faculty of Electrical Engineering and Informatics, \\ Technical University of Kosice, Letna 9, 04200 Kosice, Slovak Republic, tel. +421 55602 3010, \\ e-mail: samuel.zuk@tuke.sk, alena.pietrikova@tuke.sk, igor.vehec2@tuke.sk
}

\begin{abstract}
In this paper, characterization and realisation of planar thick film rain sensor based on capacitive principle is presented. By using three different pastes (inks) for realisation of capacitive sensor it was found out that sensor produced by carbon ink is not suitable for use in this application because it shows no change in measured capacitance when temperature or humidity level varies. The best characteristics were obtained by using silver conductive paste. Capacity of capacitive sensor realized by polymer silver paste shows rising tendency when temperature and humidity values rises.
\end{abstract}

Keywords: capacitive principle, rain sensor, thick film technology

\section{INTRODUCTION}

Flexible electronics is increasingly replacing traditional rigid electronics in low power applications as consumer and industrial. The most common factor for using flexible electronics is lower cost and smaller environmental impact in comparison with traditional electronics.

Nowadays, flexible electronics is more commonly used in sensing applications. One of the possible sensing applications may be planar film rain sensor based on capacitive principle and that is manufactured by thick film technology.

For use not only in sensing applications polymer printing pastes must have good printing properties to obtain requesting print resolution. Especially for automotive applications, cured pastes must have good adhesion to flexible substrate, enough flexibility to withstand folding, and adequate electrical conductivity (resistance).

As an alternative to standard thick film technology, ink printing technology offers advantages for realisation of high resolution planar structures or in the field of sensors.

In this paper, analysis of planar thick (ink) film rain sensor based on capacitive principle is presented. The effort is to produce a flexible rain sensor as an alternative to standard rigid sensor that is highly sensitive to temperature and humidity variations.

Capacitive planar rain sensor can find application for example in automotive electronics or in another industry fields where humidity is important property. Flexible rain sensors based on capacitive principle were not realized yet.

\section{CAPACITIVE SENSING PRINCIPLE}

Capacitive sensors are being used for different sensing applications, e.g. for detection of conductive object's position or for nonconductive object's thickness. Typical measurement ranges for commonly used industrial type capacitive sensors are about $10 \mu \mathrm{m}$ to $10 \mathrm{~mm}$ with up to $2 \mathrm{~nm}$ resolution [1]. Because of their principle of operation, capacitive sensors cannot be used in harsh environment.

Capacitor is formed by two parallel plated electrodes. Capacitance $\mathrm{C}$ of such a capacitor can be calculated using equation [1]:

$$
C=\frac{\varepsilon_{0} \varepsilon_{r} A}{d}
$$

where $\varepsilon_{0}$ is permittivity of free space, $\varepsilon_{r}$ is relative permittivity of material between electrodes, $A$ is the area of capacitor's electrodes and $d$ is the distance between electrodes. Eq. (1) is provided only to present all parameters that affects capacity value of standard parallel plate capacitor or some specific planar capacitive sensor structures. More sophisticated equation [2] that contains the lines width and spacing, thickness and relative permittivity of substrate and surrounding environment and many more parameters, is required to calculate capacity of planar comb sensor structure. It is therefore recommended to use some of the available multiphysics software tools to model and calculate the parameters of specific sensor structure.

There are two common possibilities (methods) for measurement of capacitance between sensor's electrodes for different sensing applications [3]:

1. Self-capacitance (Fig. 1a) technique is based on the measurement of capacitance between one sensor electrode and ground. Rising of humidity of the air changes relative permittivity value that results in increasing of measured capacitance value.

2. Mutual capacitance (Fig. 1 b) principle for measurement of capacitance uses two measurement electrodes - transmitting and receiving. This measurement method is more immune against undesired environment impact. For this reason, we used mutual capacitance sensing method for this study.

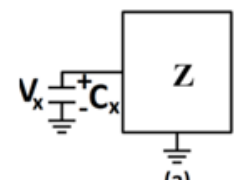

$\overline{\bar{a}}$

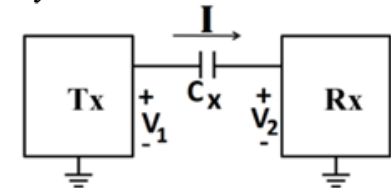

(b)
Fig. 1 Self-capacitance (a) and mutual capacitance (b) sensing principle

Measurement of different variables can be obtained by using capacitive measurement principle. For this study, we will focus on two of the variables that significantly affect the capacitance value of capacity sensor. 
Relative permittivity of the environment (in this study air) is highly dependent on the amount of saturated water vapour. With the higher amount of saturated water vapour the measured capacity value rises. Humidity measurement based on this principle is used for realisation of planar capacitive rain sensor. However, capacitive sensors are also sensitive to temperature changes and measured capacity is proportional to the change of sensor's temperature.

\subsection{RAIN SENSING IN AUTOMOTIVE INDUSTRY}

There are many possibilities of rain sensing methods [4]; some of them are explained in following subchapters.

\subsubsection{RAIN SENSOR BASED ON PIEZOELECTRIC PRINCIPLE}

This type of system uses a crystal - piezo element that can be considered as a microphone. Droplets of rain falling on the windscreen of a car cause formation of sound waves of certain frequency that are transmitted through the windscreen. The piezo sensor element captures these waves, and the electronics can then process a signal, which then attempts to distinguish between rain and other sounds. This system is very sensitive and can be easily interfered with by passing cars, resulting in incorrect or delayed start of wipers. Another drawback of this type of rain sensor is the insensitivity to fine drizzle or moisture on the windscreen. For these reasons, this method of rain sensing did not apply in the automotive industry.

\subsubsection{RAIN SENSOR BASED ON OPTICAL PRINCIPLE}

Fig. 2 shows a working principle for the operation of a rain sensor based on optical principle.

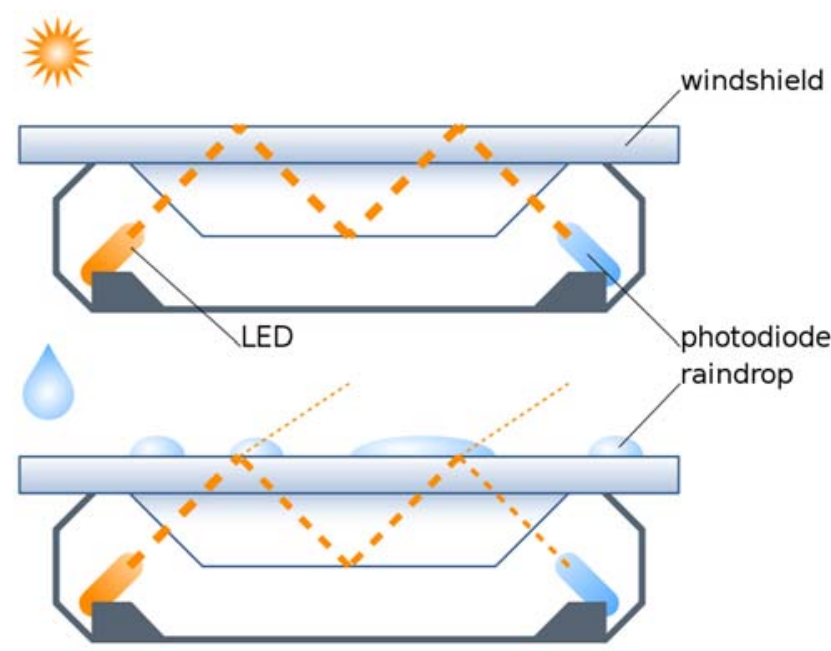

Fig. 2 Optical rain sensor principle [4]

The LED diode sends the infrared light to the windscreen of the vehicle. The internal optics of the module provides a complete internal reflection of the light beam emitted by the diode. This reflected light generates a current in the receiving photodiode.
When rain drops on the vehicle's windshield, some of the light rays are scattered into the surrounding environment as the angle of reflection of these beams changes at the glass and water interface. As a result of this physical phenomenon, less light on the photodiode will occur. Then the intensity of the rain can be calculated from the difference in the amount of reflected light. The signal representing the amount of reflected light is scanned by the microprocessor, which decides whether it rains on it, and how quickly wipers should be wiped out.

One of the biggest challenges for the optical rain sensor is that the receiving diode does not only accept the light reflected from the car's windscreen, but also the light of the surrounding environment. Changes to this light can be interpreted as drops of rain on the windscreen, causing the wiper to start. This results in increased wear of wipers and risk of scratching the windscreen. The microcontroller distinguishes sunlight from the modulated light emitted by the diode. Another advantage of the microcontroller is that it can compensate the characteristics of the photodiode, allowing using cheaper photodiode that reduces the cost of producing a light rain sensor. An associated feature is the level of ambient lighting that can be used to control the vehicle's lighting.

\subsubsection{RAIN SENSOR BASED ON CAPACITIVE PRINCIPLE}

The rain sensor based on capacitive principle is made up of two copper wires that are close together and are realized on a printed circuit board (PCB) mounted on the windscreen in the interior of the vehicle. Capacitive measurements are performed across the face of the capacitive sensor on the windscreen, so only the drops of rain that will be found in the front area of this sensor will be detected. This method offers a larger surface for detecting rain as sensor based on optical principle. The copper conductors realized on $\mathrm{PCB}$ can be arranged in different shapes and sizes. The most commonly used shaped is so-called comb structure.

With a capacitive sensor realized as s two-wire sensor, the basic design is very important. The width of the wires, the gaps between them and the overall layout size are important. All of these aspects have a major impact on the overall performance of the system. Significant influence on sensor efficiency has dielectric constant of materials. The dielectric constant of the material is the ability of the material to transfer the electric field. Higher valuesindicate better transmission of electric fields. The dielectric constant of the air is 1, for FR4 PCB is about 4 and for the glass is about 4.5-6. The windshield comprises a thin layer of plastic inserted between the two sheets of glass. There should be shielding beneath the circuit board to prevent undesired capacity changes from the interior of the vehicle.

\section{PLANAR CAPACITIVE RAIN SENSOR DESIGN AND MANUFACTURING}

As substrate, polyimide film foil DuPont Kapton $\mathrm{HN}$ of $125 \mu \mathrm{m}$ thickness was used [5]. Three different pastes (inks) - silver conductive paste Electra ED2000, highly conductive silver colour XZ250 and carbon ink 26-8203 from Britrade were used for characterization of realized 
sensors. Selected properties of thick film pastes used for printing are listed in Tab. 1.

Tab. 1. Selected properties of polymer pastes used for this study $[6,7,8]$

\begin{tabular}{cccc}
\hline Parameter & Ag paste & $\begin{array}{l}\text { Ag } \\
\text { colour }\end{array}$ & Carbon ink \\
\hline $\begin{array}{c}\text { Resistivity } \\
{[\mathrm{m} \Omega / \square]}\end{array}$ & $30-35$ & 32 & $<70$ \\
$\begin{array}{c}\text { Viscosity [Poise] } \\
\text { at } 25^{\circ} \mathrm{C}\end{array}$ & $40-60$ & $30-50$ & $70-80$ \\
\begin{tabular}{c} 
Thickness [ $\mu \mathrm{m}]$ \\
\hline
\end{tabular} & $20-25$ & $10-12$ & $10-15$ \\
\hline
\end{tabular}

After standard thick film screen printing process, all realized sensors were characterized using climatic chamber. As sensors are intended to be used in the cars, they were characterised at three different temperatures $25^{\circ} \mathrm{C}, 50^{\circ} \mathrm{C}$ and $70^{\circ} \mathrm{C}$ with humidity levels of $35 \%$ rh, $50 \% \mathrm{rh}, 70 \% \mathrm{rh}$ and $90 \% \mathrm{rh}$. Typical graph for testing process of realized sensor structures at temperature of $25^{\circ} \mathrm{C}$ is presented in Fig. 3.

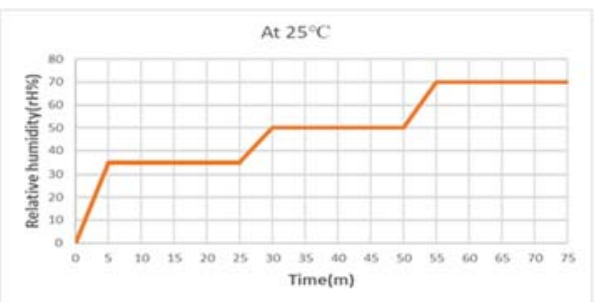

Fig. 3 Characterization graph for testing of realized sensor structures at temperature of $25^{\circ} \mathrm{C}$

For this study, planar capacitive sensor with comb structure, with $200 \mu \mathrm{m}$ trace width and $290 \mu \mathrm{m}$ spacing between traces and totally of 40 comb pairs was realised. Motive of this structure is presented in Fig. 4.

To obtain reliable results, there were printed four capacitive structures at same substrate (Fig. 4). These four sensors were measured simultaneously and the final capacitance value was calculated as an average of all four measured values. Realized sensor structures were characterised by using commercially available evaluation board from Texas Instruments (FDC2214EVM [9]). This evaluation board allows capacitance measurement using signal of sinusoid shape with frequency of $10 \mathrm{kHz}$ to $10 \mathrm{MHz}$ and amplitude of approx. 1.4 $\mathrm{V}_{\mathrm{PP}}$.

It is important to realize that within capacitive planar sensing system we measure relative permittivity of air. Humidity affects the permittivity of the air, as increasing the moisture content of the water vapour increases. This follows from the nature of this sensor.

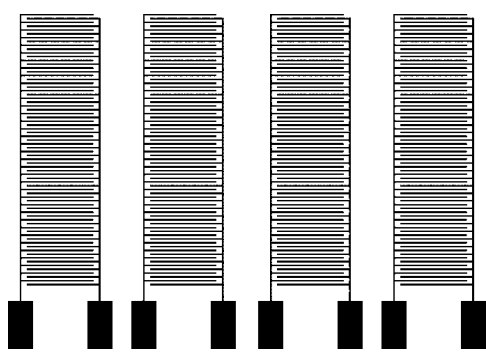

Fig. 4 Realized planar capacitive sensor structures

\section{RESULTS AND DISCUSSION}

Planar capacitive rain sensor realized by Ag paste on PI substrate is shown at Fig. 5. Fig. 6 to Fig. 8 presents obtained results of characterized capacitive sensors realized on Kapton PI substrate. The planar capacitive system allowed us to analyse changes in temperature and humidity of the air. As can be seen in Fig. 6, capacitive sensor printed by Electra ED2000 silver conductive paste shows rising tendency of its capacitance when temperature and humidity values rises. Capacitive sensor realized by highly conductive silver colour XZ250 (Fig. 7) shows very similar behaviour as sensor printed by Electra ED2000, but changes in measured capacitance are not so expressive. Unlike these two pastes, capacitive sensor realized by carbon ink 26-8203 showed almost no changing in capacitance when variation of temperatures or humidity levels (Fig. 8).

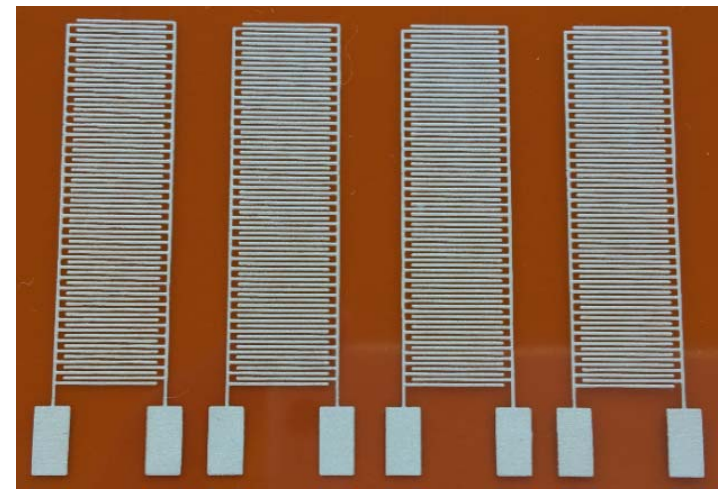

Fig. 5 Planar capacitive rain sensor realized by Ag paste on PI substrate

The pastes (inks) used have different conductivity, but this does not significantly affect the sensitivity of this sensor. Sensitivity of the planar capacitive sensor system has the greatest influence on the geometry of conductive electrodes.

The sensitivity of the planar capacitive rain sensor to moisture is evident as the very thin layers of Ag colour have a lower capacity than the sensor realized by Ag paste, which is coarser. In addition, in the case of carbon ink, characterized by higher resistivity, the sensitivity to moisture was not observed.

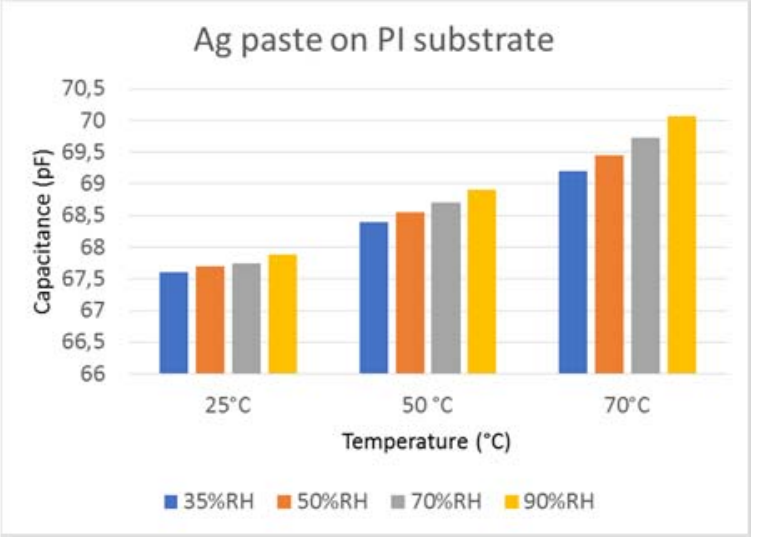

Fig. 6 Measured results of capacitive sensor realized by Electra ED2000 silver paste on Kapton PI substrate at different temperature and humidity levels 


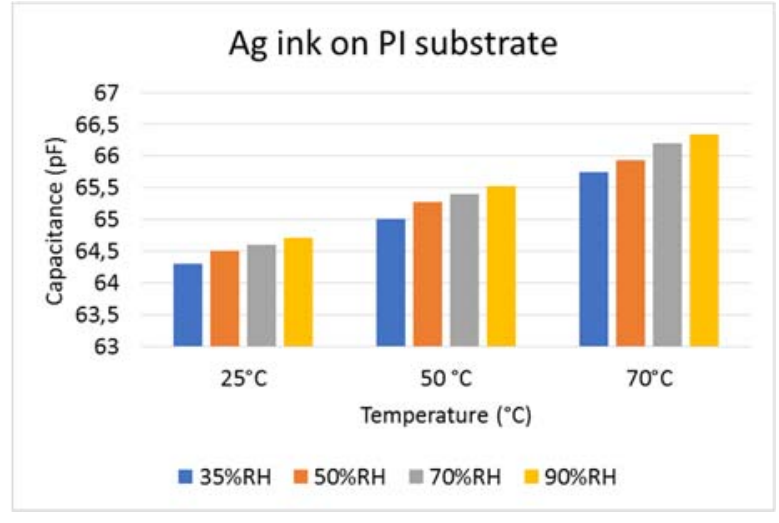

Fig. 7 Measured results of capacitive sensor realized by XZ250 silver colour on Kapton PI substrate at different temperature and humidity levels

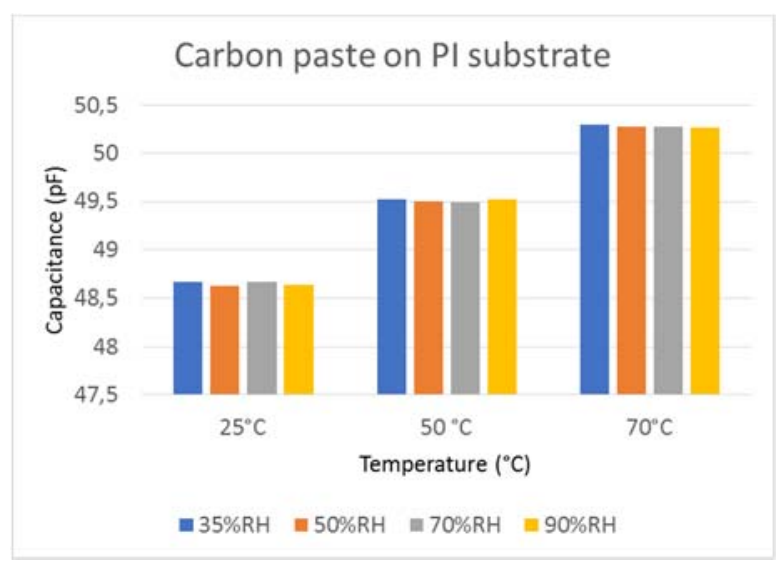

Fig. 8 Measured results of capacitive sensor realized by 26-8203 carbon ink on Kapton PI substrate at different temperature and humidity levels

However, in all three cases, increasing of temperature has caused increasing of capacity. Capacity values of the sensor realized by carbon ink were generally lower in comparison to sensors realized by Ag paste or ink. In addition, with an increase in temperature and also an increase in moisture, the Ag paste structure was much more sensitive. E.g. at $70^{\circ} \mathrm{C}$ there was an increase in $\mathrm{Ag}$ paste capacity at a rise in humidity from $35 \%$ rh to $90 \%$ rh for $1.3 \%$, whereas the increase in capacity on the $\mathrm{Ag}$ colour sample was only about $1 \%$ under these conditions (Fig. 9).

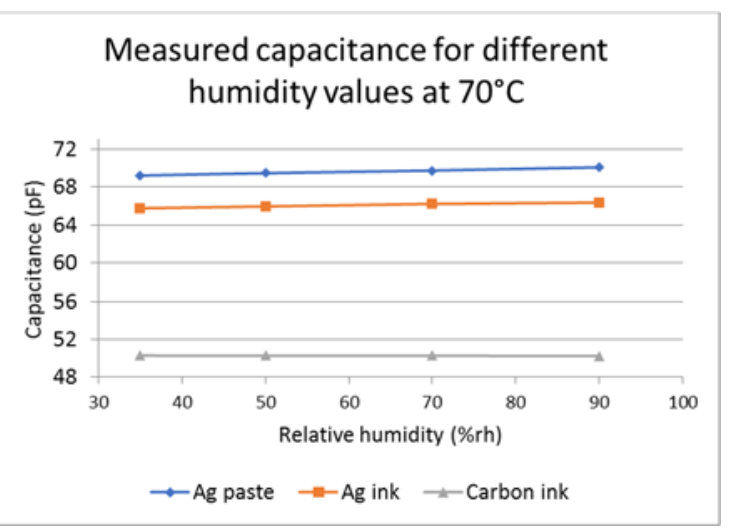

Fig. 9 Measured capacitance for different humidity values at $70^{\circ} \mathrm{C}$
The sensitivity of the capacitive sensors is very closely related to the precision of applying the conductive pastes (inks) to the substrate. We found that with such small dimensions the distance between the electrodes within the sensor was different. Measured line widths and spacing between lines of the capacitive comb sensor structures realized by silver colour and carbon ink are presented on Fig. 10 and Fig. 11, respectively.

We used only one type of mesh (325 mesh) for the screen printing, with the viscosity of the applied materials being different (Tab. 1). The more accurate the electrode application, the higher the sensitivity of the sensor and the measurements are more precise and repeatable. Thus, it can be stated that in addition to the conductivity of the applied materials, the accuracy of the applied technology also affects the sensitivity of the sensor.

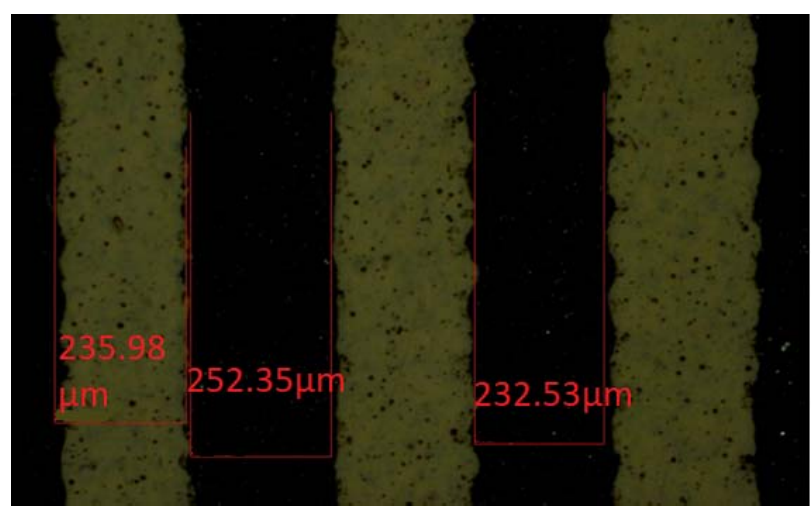

Fig. 10 Measured lines and spaces dimensions on the capacitive rain sensor sample made by $\mathrm{Ag}$ colour

Because of different viscosity values of materials used for realisation of planar capacitive rain sensor in this study (Tab. 1), the constant widths of the sensor comb electrode structure were not respected, but the thickness of the applied layers of all three materials was approximately the same. The largest relative area on a given surface had material with the lowest viscosity, silver paste, where the viscosity change was pronounced the most. Since the difference between the electrical conductivity of the materials used is not significant and provided that there is no significant difference between the materials used to absorb moisture from the surrounding environment, we can state that the sensitivity of the capacitive sensor is influenced by the softness, respectively density of electrodes.

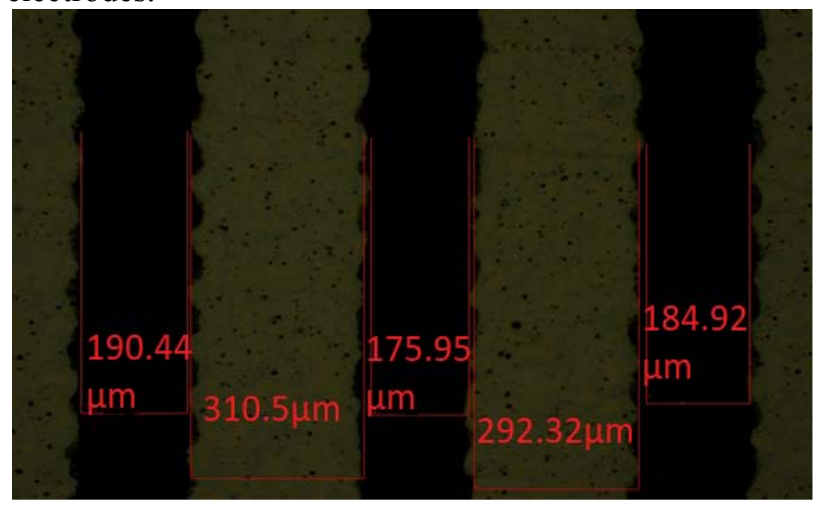

Fig. 11 Measured lines and spaces dimensions on the capacitive rain sensor sample made by carbon ink 
In our case the highest sensitivity was measured when using silver paste, where the most marked influence of temperature and humidity was measured.

As the temperature increases, the measured capacity value increases for all of the used materials, with the highest values being achieved for a silver-based conductive paste. In the case of silver-based materials, the increase in moisture also increases in capacity, and the carbon based paste has not shown this dependence. It can be said that the precision of the sensors is affected by the conductivity of the material used. In addition, the accuracy of the application of the conductive layers, which is related to the viscosity of the applied materials, has a significant influence on the achieved capacity values. The viscosity affects the possibilities of the rough-layer technology to achieve a constant distance between the electrodes and thus the repeatability of the results of the capacity measurements.

Because capacitive sensors are very sensitive to temperature changes, using temperature sensor and software compensation for rain sensing application is required.

The aim of this work was to develop planar capacitive sensor structure sensitive only to humidity changes. However, as the measurements show, the measured capacity is also influenced by the ambient temperature itself (undesired phenomenon), which must be compensated by using an additional temperature sensor.

\section{CONCLUSIONS}

Presented planar capacitive rain sensor based on thick film technology offers another possibility for sensing the rain or humidity not only in automotive industry and based on measurement results, it can be used as a suitable and reliable replacement of capacitive rain sensor realized on rigid $\mathrm{PCB}$ substrate.

The sensitivity of the capacitive sensor is influenced by the softness, respectively density of electrodes. The highest sensitivity was measured when using silver paste, where the most marked influence of temperature and humidity was measured.

As the temperature increases, the measured capacity value increases for all of the used materials, with the highest values being achieved for a silver-based conductive paste. In the case of silver-based materials, the increase in moisture also increases in capacity, and the carbon based paste has not shown this dependence. It can be said that

The precision of the sensors is affected by the conductivity of used material. The viscosity affects the possibilities of the rough-layer technology to achieve a constant distance between the electrodes.

Evaluated capacitive planar sensing system is very sensitive not only for humidity but to temperature changes as well as.

\section{ACKNOWLEDGMENTS}

This paper was developed with support of the Project "Centrum excelentnosti integrovaného výskumu a využitia progresívnych materiálov a technológií $\mathrm{v}$ oblasti automobilovej elektroniky" (Centre of Excellence of Integrated Research and Exploitation the Advanced materials and Technologies in the Automotive Electronics), ITMS 26220120055, that is co-financed from Structural Funds EU ERDF within Operational Program Research and Development OPVaV-2009/2.1/03-SORO and preferred axis 2 Support of Research and Development.

This work was supported by APVV project No. APVV14-0085: Development of New Generation Joints of Power Electronics Using Nonstandard Sn-Based Alloys.

This work was supported by KEGA project under the contract No. 021TUKE-4/2017: Promotion of modern teaching methods at the Laboratory of automotive electronics.

This work was supported by VEGA project under the contract No. 1/0141/18: Experimental and theoretical behaviour study of newly developed miniature touch capacitive and inductive sensors realized by film technologies.

\section{REFERENCES}

[1] HU, X.: Planar capacitive sensors - designs and applications, Sensor Review, Vol. 30, No. 1, pp. 24$39,2010$.

[2] GONZALEZ, G. - KOLOSOVAS, E. - LOPEZ LUNA, E. - HERNANDEZ-ARRIAGA, H. GONZALEZ, F.: Design and Fabrication of Interdigital Nanocapacitors Coated with $\mathrm{HfO}_{2}$, Sensors, Vol. 15, No. 1, pp. 1998-2005, 2015.

[3] ZUK, S. - PIETRIKOVA, A.: Capacitive sensors realized on flexible substrates, ElectroScope, Vol. 2017, No. 2, pp. 1-5, 2017.

[4] MAREK, J. - TRAH, H.P. - SUZUKI, Y. YOKOMORI, I.: Sensors for Automotive Applications, 4th ed. New Jersey: Wiley-VCH Verlag GmbH, 2005, pp. 474-480.

[5] DUPONT USA: Kapton HN General-Purpose Polyimide Film, Technical Datasheet, http://www.dupont.com/content/dam/dupont/product s-and-services/membranes-and-films/polyimdefilms/documents/DEC-Kapton-HN-datasheet.pdf

[6] ALLEN WOOD ASSOCIATES, INC.: Electra ED2000 Silver Conductive Paste for Rigid Circuit Boards, Technical Datasheet, http://allenwoodsgroup.com/pdf/ED2000.pdf

[7] BRITRADE SLOVAKIA: XZ250 Highly Conductive Silver Colour, Technical Datasheet, http://www.britrade.sk/storage/file/striebornapasta.pdf

[8] BRITRADE SLOVAKIA: Conductive Carbon Paste 26-8203, Technical Datasheet, http://www.britrade.sk/storage/file/pasta-flexy.pdf

[9] TEXAS INSTRUMENTS: FDC2214 with Two Capacitive Sensors Evaluation Module, Technical Datasheet, http://www.ti.com/lit/pdf/snou138.

Received October 19, 2018, accepted November 27, 2018 


\section{BIOGRAPHIES}

Samuel Zuk was born on 1990. In 2015 he graduated (MSc) with distinction at the Department of Technologies in Electronics of the Faculty of Electrical Engineering and Informatics at Technical University of Košice. Now, he is a PhD. student at the same department. His scientific research is oriented to inductive and capacitive sensors based on film technologies.

Alena Pietrikova is full professor (2007) of Electrotechnology and Materials at the Faculty of Electrical Engineering and Informatics at Technical University of Košice, Slovak Republic. Her research work is concentrated on problems concerned with modern materials and technologies in electronics (film technologies assembling technologies in electronics, and materials for electronics). She is an author or co-author of more than 280 research articles in international journals or conference proceedings, 5 patents and 5 books.

Igor Vehec is assistant professor (2009) at the Faculty of Electrical Engineering and Informatics at Technical University of Košice, Slovak Republic. His research work is focused on technologies in electronics, especially on thick-film and LTCC technologies and wire bonding. He is an author or co-author of more than 80 research articles in international journals or conference proceedings including 4 current content journals and 1 patent. 